\title{
Corpo narrativo: um lugar que me atravessa
}

Marcelo Campos*

RESUMO: O artigo procura problematizar as relações entre corpo e lugar nas obras da arte contemporânea brasileira. Buscam-se referências em trabalhos nos quais a presença do corpo do artista se faz de modo narrativo. A análise se detém na produção de Berna Reale, Brígida Baltar, Efrain Almeida, José Rufino e Rosana Paulino. Ao mesmo tempo, pensa-se o lugar como condição narrativa nas teorias de Nestor Garcia Canclini e Homi Bhabha. A arte contemporânea, a partir dos anos 1990, potencializou a ideia de autoficção coadunada com a presença do narrador em primeira pessoa. A constância do sujeito na narrativa evidencia uma mudança na compreensão das dicotomias entre público e privado. Hoje, a localidade se reelabora como negociação de um presente conectado em instantâneos. E o corpo permanece ativando esferas de significados.

Palavras-chave: arte contemporânea brasileira, brasilidade, corpo, autorrepresentação

ABSTRACT: The paper aims to discuss the relationship between body and place in the works of contemporary Brazilian art. References are sought on works in which the presence of the artist's body becomes the

* Marcelo Campos é professor adjunto do Departamento de Teoria e História da Arte do Instituto de Artes da Universidade do Estado do Rio de Janeiro (UERJ). 
narrative mode. The analysis delves into the production of Berna Reale, Brigida Baltar, Efrain Almeida, José Rufino and Rosana Paulino. At the same time, it is thought the place as narrative condition in Nestor Garcia Canclini theories and Homi Bhabha. Contemporary art from the 1990s enhanced the idea autofiction, coalescing with the presence of the firstperson narrator. The constancy of the subject in the narrative indicates a change in understanding the dichotomies between public and private. Today, the location trading as a present connected in snapshots. And the body remained activating spheres of meaning.

Keywords: Brazilian contemporary art, national identity, body, selfrepresentation

A ferramenta infográfica apresenta imagens reais e um passeio contínuo pelo bairro da infância. Podemos ver a antiga moradia, o jornaleiro, a venda, a igreja, a escola. Diante das imagens, pendulamos entre um sentimento melancólico de preservação de relíquia e a vontade de enfrentar o futuro, sensações misturadas à inevitável veleidade de apagamento do próprio recurso. Como substituir o caminhar? Mas, o modo como um corpo atravessava tais lugares permanece intacto na memória. O lugar atravessa o corpo no mesmo istmo em que é atravessado pelo sujeito.

Nas imagens projetadas na sala do museu, a artista empenha-se em executar gestos pregnantes. Em um dos vídeos, apresenta-se disfarçada de mulher rica, com colares de pérolas, tailleur, cabelos escovados, preservados em laquê. A personagem dirige uma biga, antigo carro de guerra de duas rodas, originalmente puxado por cavalos. Agora, em um bairro pobre, periférico, do Brasil, a biga é conduzida por porcos que chafurdam diante das câmeras. A rua enlameada, as casas sem reboco, as crianças descalças configuram a locação próxima às condições de abandono do poder público. Ali, exibem-se, em latência, os perigos de uma sociedade neoliberal, na qual a distinção entre as esferas públicas e privadas mudam de função. De que maneira conjugar consumo capitalista e condições de habitação? O que se configura como característica de um lugar e o que se tornou ponto de um descaso problemático? 


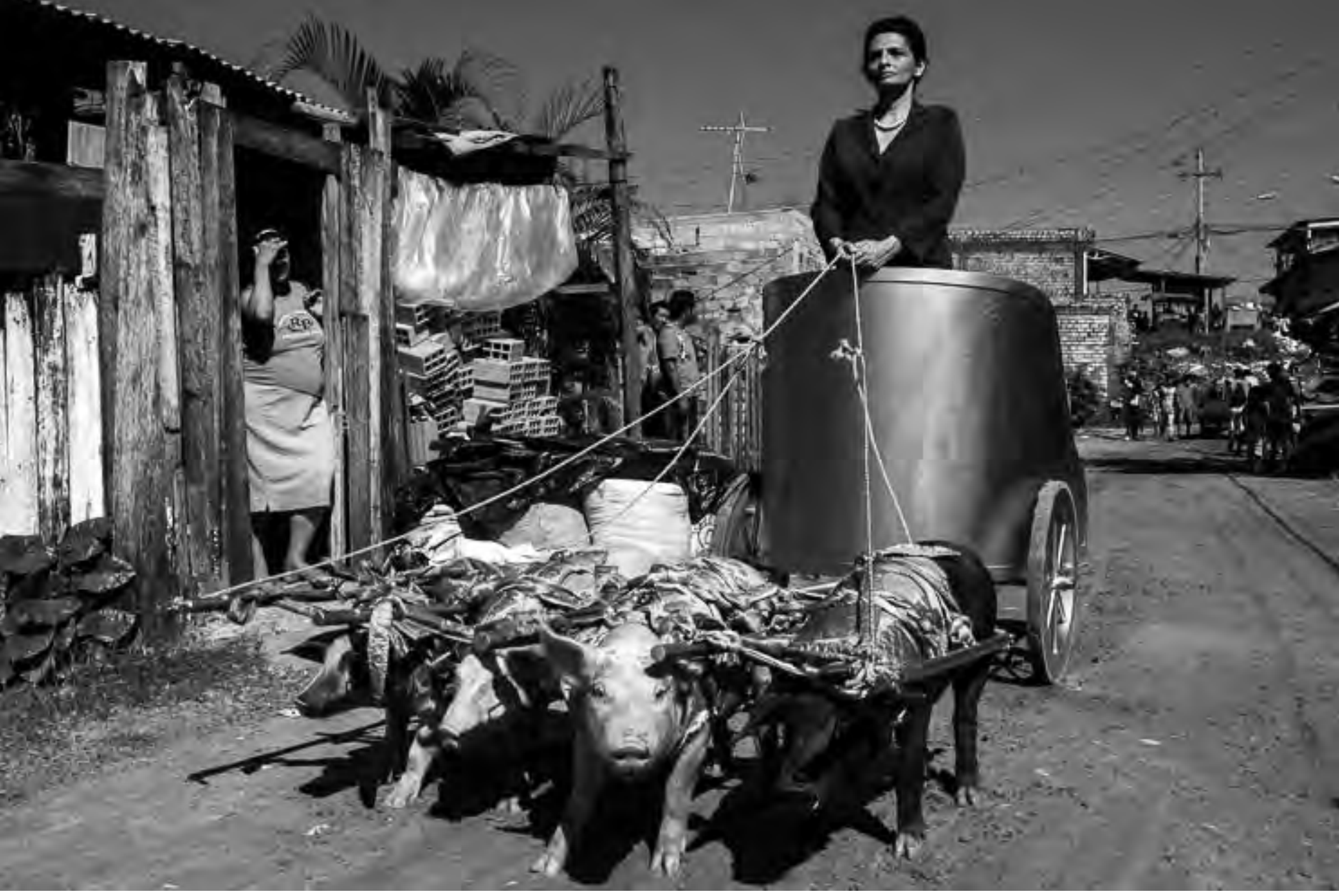

Berna Reale

Soledade, 2013.

vídeo

Registro fotográfico: Janduari Simões 
O lugar atravessa a personagem, mas agora, em conflito. Ela não pertence àquela casta, àquele grupo, àquele tempo. Berna Reale consegue nos colocar diante de ambivalências, contradições. E, acima de tudo, mantém-se sem cacoetes de arte contemporânea. A personagem é farsa. Uma história contada pela segunda vez, como nos ensinara Karl Marx. E Berna se agarra a esta condição, com tailleur feito na costureira, longe de Coco Chanel, perto do Mercado Ver-o-peso. Assim, Belém do Pará atravessa seu corpo, ainda que não consigamos responder: "de que lugar trata uma paisagem?", pergunta lançada por outra artista, Brígida Baltar, em vídeo produzido no sertão brasileiro.

O lugar que atravessa um corpo foi um dos pontos de inflexão do trabalho de Brígida Baltar, Efrain Almeida, José Rufino, Rosana Paulino, entre outros artistas surgidos na cena brasileira dos anos 1990, e continua potente em trabalhos como os de Berna Reale. A arte contemporânea brasileira, desde os anos 1960, acostumara-se a refletir sobre características identitárias em objetos de apropriação, advindos da cultura popular. Por outro lado, a consciência espacial misturava-se a questões socioculturais, como nas relações entre as favelas e a obra de Hélio Oiticica. Porém, a geração que surgira com as discussões dos anos 1990 enfrentara a condição hibridizada entre vida privada e pública. As categorias antes ampliadas como classe e gênero tornaram-se "consciência das posições do sujeito", denominação dada pelo indiano Homi Bhabha (2003). Com o surgimento do vírus da AIDS, o sexo se transformara em discurso, campanhas de prevenção, luta contra preconceitos veiculados no horário nobre da TV. O corpo, então, virou panfleto para tais discussões. Narrar as diferenças, segundo Canclini, marca um desejo de convergência, mas nunca uma "unicidade de termos". (CANCLINI, 2009, p. 57) Problematizam-se o gênero, a sexualidade, a etnicidade. E, então, tais narrações passam a atravessar o corpo dos artistas.

Porém, que lugar servirá como vértice para tais discursos? Aqui teremos a grande mudança empreendida por artistas que se empenham em relatos sobre seus amantes, seus amigos, seus diários, sua casa, sua cama. Os sujeitos gritarão a partir de "entre-lugares", "nos excedentes da soma das partes das diferenças". (BHABHA, 2003, p. 20) Tal articulação, afirmará Bhabha, é uma "negociação complexa" pelo direito de se expressar a partir das margens, das fronteiras, reinscrevendo a condição do contingente histórico, localizado, pessoal. Questionase o "modo de representação da alteridade" (BHABHA, 2003, p. 107) que agora deixa os discursos grandiloquentes para assumir a micronarrativa desde a casa, desde o corpo. 
Percebemos, na arte brasileira, Brígida Baltar fazer de seu corpo um lugar a ser atravessado, metamorfoseado, vivido. Em projetos iniciais, Brígida explorou a fisicalidade de seu próprio ateliê, fazendo experimentações, cavando buracos na parede, retirando o pó de tijolo, coletando goteiras da casa, criando simbioses com personagens como a abelha, por exemplo. E quem enfrenta a narração é o corpo da artista; próximo, de dentro da casa, estranhando o lugar e se deixando atravessar por ele. Efrain Almeida faz da escultura uma possibilidade de autoimagem, autoficção, na qual o lugar geográfico, o interior do Ceará, passa a se apresentar na madeira característica de santeiros do interior, a umburana, deixando, muitas vezes, o lugar atravessar seu corpo, apresentado em autorretratos. Esta arte assumira a primeira pessoa como situação, um lugar que questionara o formalismo autônomo, apresentando problematizações sobre a diferença, sobre a desigualdade. José Rufino traz os arquivos familiares, tradições ligadas à cultura canavieira, em cartas de seus ascendentes paraibanos. Vemos, no uso de um mobiliário colonial, o Brasil dos senhores de engenho, atualizado, posteriormente, nas discussões sobre o corpo desaparecido da ditadura militar. Rosana Paulino faz da etnicidade uma condição, observando a herança familiar em imagens enclausuradas de retratos impressos sobre bastidores, instrumentos de bordar, com rostos de negros costurados nos olhos, na boca. Ali, as representações se coadunam, o ícone de Escrava Anastácia mescla-se às fotos corriqueiras de menores negros infratores. 


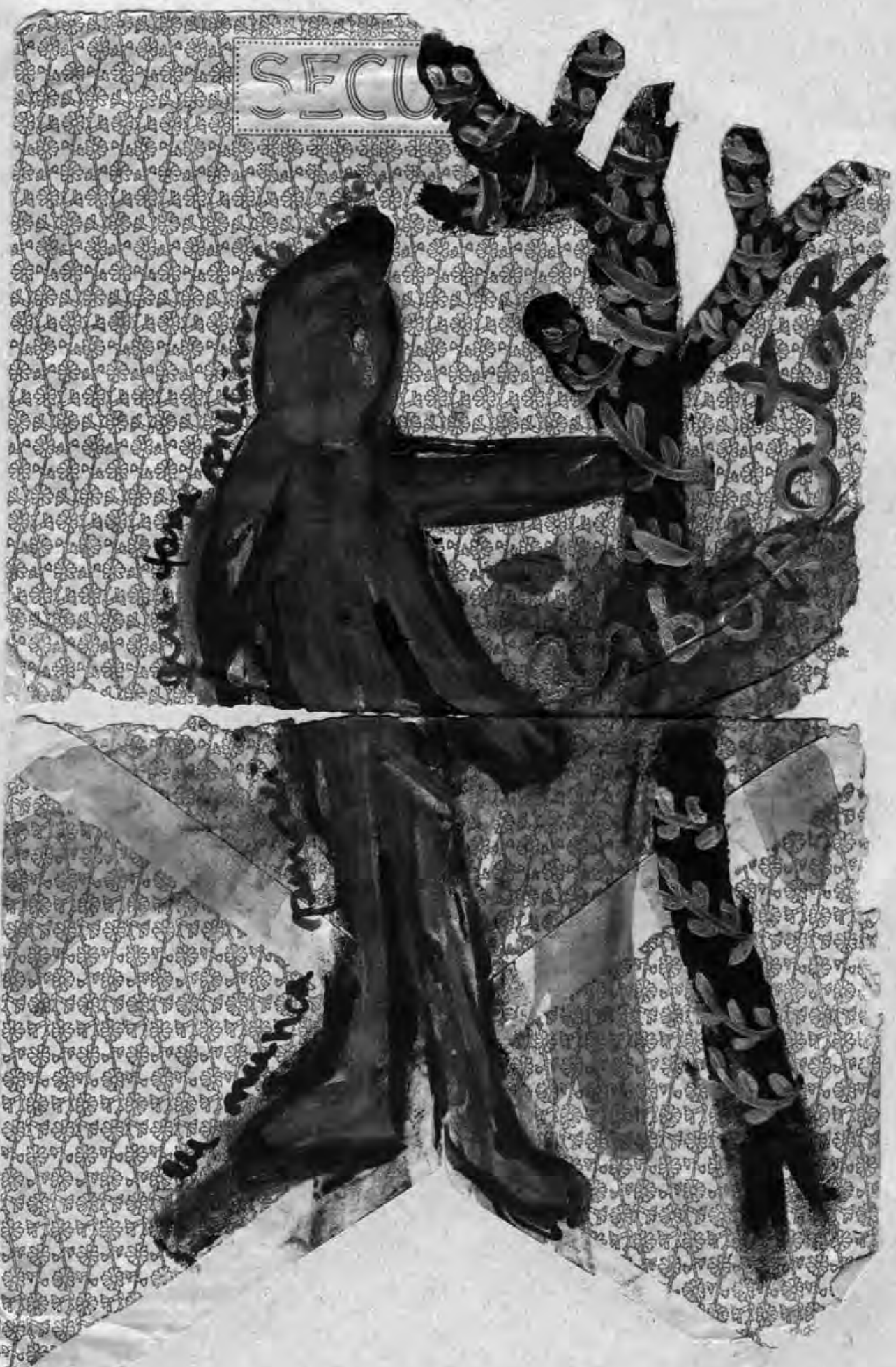

José Rufino

Cartas de areia, 1980-

desenho (têmpera, sanguínea e lápis sobre envelope de família) $15,6 \times 24,6 \mathrm{~cm}$ 


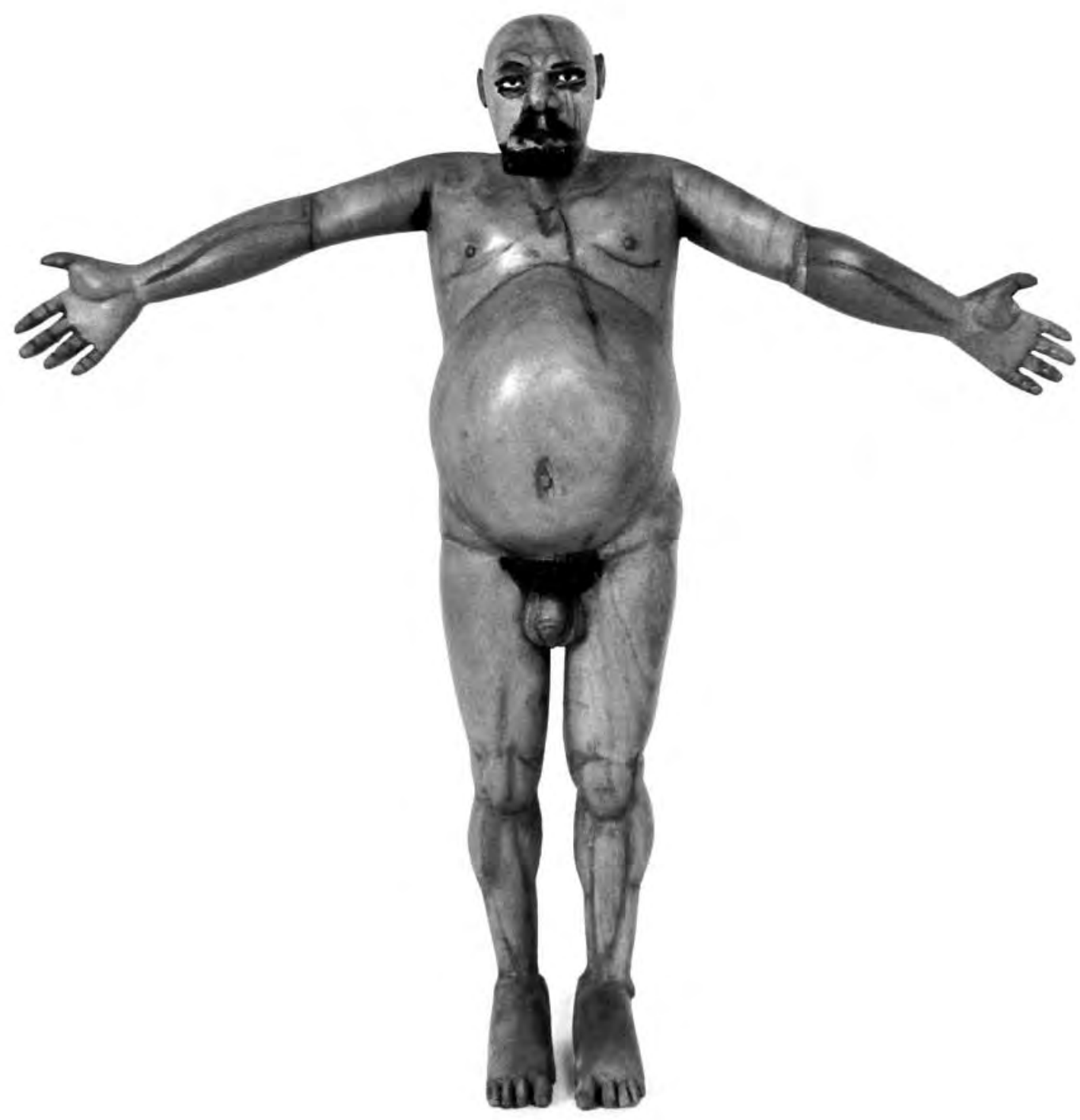

Efrain Almeida Autorretrato vitruviano, 2013.

umburana e óleo $27 \times 27 \times 6 \mathrm{~cm}$ Cortesia: Galeria El Museo 
Assim, os lugares atravessam o corpo. Percebemos, como nos esclarecera Homi Bhabha (2003), que a localidade só vale, só vence, quando precisa ser negociada. O lugar, a nação preenche o vazio deixado por várias diásporas, um lugar de partida, de separação, de desagregação. E a arte exercita a "metaforicidade" (BHABHA, 2003, p. 201) que empreende um retorno, agora consciente da perda, mas presentificado por um outro evento, aquele que o artista propõe para refazer laços de confiança com o público. A brasilidade na arte contemporânea é, então, um modo de negociar a presentificação destes eventos ligados a problemas sociais, às desigualdades praticadas pelo sistema da arte, concentrado no sudeste, à diferença dos discursos de gênero e de etnicidade. Exercita-se um modo de perceber as fronteiras, as quebras, a autonomia como ameaça de desconexão, silêncio das anomias.

Canclini nos alerta que existe uma "luta pela significação", a partir da "cultura do instantâneo sem história". (CANCLINI, 2009, p. 220) Conectar-se e desconectar-se. Organizar bases sólidas ou solidificar a fugacidade dos instantes? Evaporam-se as utopias e responde-se ao risco de exclusão "a beleza é uma qualidade do acontecimento, não do objeto", decretara Zygmunt Bauman. (apud CANCLINI, 2009, p. 219) A experiência corporal na arte deixa evidente esta sensação de que "tudo está no instante" e que precisamos "captar sua densidade". (CANCLINI, 2009, p. 219) Pensar a periferia de Belém do Pará, o sertão cearense, a Casagrande paraibana ou um ateliê em Botafogo é conferir densidade a histórias irreproduzíveis, a sensações de diáspora, exílio, perda, memória e melancolia.

O corpo, no entanto, pode agir sobre a perda. Deste modo, Berna Reale deixa-se atravessar pelo Brasil periférico, na favela de Belém do Pará. Um lugar que pode se apresentar conectado ao Google Street View da tela do computador, mas que carece de descrição particularizada, inventiva, pois no ato de conectar-se ficamos cada vez mais diante do assombro de instantâneos sem história, mas que o corpo, nas falácias do presente, tratará de percorrer, de projetar em um tempo memorável, narrável, sobretudo.

O lugar só existe na arte como um corpo narrativo.

\section{Referências}

BHABHA, Homi. O local da cultura. Belo Horizonte: Editora UFMG, 2003.

CANCLINI, Nestor Garcia. Diferentes, desiguais, desconectados. Rio de Janeiro: Editora da UFRJ, 2009. 